\title{
CMEARTICLE \\ Doctor, my dentist wants your opinion
}

Fang Yee $\underline{\mathrm{Chee}^{1}}$, MBBS, MRCP, Choon How $\underline{\mathrm{How}}^{2}$, MMed, FCFP

Mr Jack is a regular patient who sees you for his hyperlipidaemia. He visited your clinic because his dentist wanted your opinion on antibiotic prophylaxis and the appropriate use of antiplatelet therapy in preparation for his tooth extraction. The patient's past records showed that he sees a cardiologist annually for mitral valve prolapse and chronic ischaemic heart disease. He had undergone an angioplasty six years ago and has been on aspirin since then. You asked for the name of your dental colleague and reached for your memorandum pad.

\section{HOW COMMON IS THIS IN MY PRACTICE? What is infective endocarditis?}

Infective endocarditis (IE) is a rare but potentially life-threatening disease. It most commonly occurs on the mitral valve, followed by the aortic valve. Streptococcus viridans, a flora found in the oral cavity, is the most common cause of native valve endocarditis (>30\% of cases).

\section{Should we continue antiplatelet agents for dental procedures?}

Dental procedures can involve the manipulation of gingival tissue, the periapical region of teeth, perforation of teeth or oral mucosa, periodontal procedures (scaling, root planning, probing, surgery and recall maintenance), extractions, endodontic instrumentation or surgery beyond apex, and biopsies. Most of these procedures would have an increased likelihood of bleeding when there is concurrent use of antiplatelet therapy. The risk-benefit ratio of each dental procedure would need to be balanced with the complications that may occur with the discontinuation of antiplatelet agents.

\section{HOW RELEVANT IS THIS TO MY PRACTICE?}

Patients with ischaemic heart disease frequently undergo dental procedures. Bleeding is a commonly encountered complication of dental procedures. It is useful for both general practitioners and dentists to weigh the risks of cessation of antiplatelet agents vs. the increased risk of bleeding, especially in patients who have recently undergone percutaneous intervention.

Traditionally, antibiotic prophylaxis was routinely given to patients with cardiac conditions associated with an increased risk of IE, before dental and other procedures. This practice was based on studies that found the presence of bacteraemia during dental treatment. However, transient bacteraemia is also caused by daily activities such as flossing and tooth brushing $(20 \%-68 \%)$, the use of wooden toothpicks $(20 \%-40 \%)$ and chewing of food $(7 \%-51 \%)$. This is more common than bacteraemia due to dental procedures. ${ }^{(2)}$ Moreover, endocarditis after dental or other procedures is rare, and no randomised controlled trials have shown that antibiotic prophylaxis works. Routine dental hygiene is, therefore, more important than prophylactic antibiotics prior to dental procedures in the prevention of IE.

The risk of antibiotic use exceeds the benefit that could be gained from antibiotic prophylaxis in most patients. ${ }^{(2)} \mathrm{A}$ study by Pallasch has shown that the absolute risks of IE from a single dental procedure are $1 / 100,000$ to $1 / 1,000,000$ in patients with valvulopathy, and 1/14,000,000 in the general population. ${ }^{(3)}$ In a large unselected population, prophylaxis with amoxicillin carries a risk of death from anaphylaxis that is five times greater than that of developing IE. ${ }^{(4)}$ It has also been reported that approximately $3 \%$ of patients develop adverse drug reactions due to amoxicillin, which is the primary antibiotic for IE prophylaxis. Of these, $82 \%$ are skin reactions. Indiscriminant use of antibiotics may contribute to an increase in resistant strains of microorganisms, which would compromise the benefits gained from antibiotic therapy due to its eventual lack of effectiveness.

\section{WHO WOULD REQUIRE ANTIBIOTIC PROPHYLAXIS DURING DENTAL PROCEDURES?}

Since April 2007, the American Heart Association (AHA) has revised its antibiotic prophylaxis guidelines for $\mathrm{IE}^{(2)}$ following an extensive review of the literature. As accurate scientific proof to support the assumption that dental procedures may cause IE in patients with predisposing cardiac conditions is still lacking, it was suggested that consideration must be given to the improvement and maintenance of oral health and hygiene, as well as better access to dental care for patients with predisposing cardiac conditions. ${ }^{(1)}$ The new guidelines state that at-risk patients with cardiac conditions in the moderate risk group no longer require prophylaxis for dental procedures, and these include patients with mitral valve prolapse, bicuspid valve disease and rheumatic heart disease. It also recommended that patients with previous

${ }^{1}$ National Heart Centre Singapore, ${ }^{2}$ SingHealth Polyclinics - Sengkang, Singapore

Correspondence: $\operatorname{Dr}$ Chee Fang Yee, Associate Consultant, National Heart Centre Singapore, 17 Third Hospital Avenue, Singapore 168752. chee.fang.yee@nhcs.com.sg 
Table I. Revised recommendations for antibiotic prophylaxis according to the American Heart Association guidelines, 2007. ${ }^{(2)}$

\begin{tabular}{|c|c|}
\hline High-risk (recommended) & $\begin{array}{l}\text { Low-risk (previously, but } \\
\text { no longer, recommended) }\end{array}$ \\
\hline Patients with a history of IE & Mitral valve prolapse \\
\hline $\begin{array}{l}\text { Patients with prosthetic cardiac } \\
\text { valve }\end{array}$ & Rheumatic heart disease \\
\hline $\begin{array}{l}\text { Cardiac transplant with } \\
\text { valvulopathy }\end{array}$ & $\begin{array}{l}\text { Congenital heart conditions } \\
\text { (e.g. ASD, VSD, HOCM) }\end{array}$ \\
\hline $\begin{array}{l}\text { CHD with prosthetic device } \\
\text { material during first six months } \\
\text { following procedure }\end{array}$ & Calcified aortic stenosis \\
\hline $\begin{array}{l}\text { Unrepaired cyanotic CHD, which } \\
\text { includes palliative shunts and } \\
\text { conduits }\end{array}$ & \\
\hline $\begin{array}{l}\text { Repaired CHD with residual } \\
\text { defects at or adjacent to the site } \\
\text { of prosthetic device or patch } \\
\text { (inhibiting endothelialisation) }\end{array}$ & \\
\hline \multicolumn{2}{|c|}{$\begin{array}{l}\text { CHD: congential heart disease; ASD: atrial septa } \\
\text { septal defect; HOCM: hypertrophic cardiomyopathy }\end{array}$} \\
\hline Yes - antibiotic prophylaxis required No - & No - antibiotic prophylaxis not required \\
\hline
\end{tabular}

Fig. 1 Algorithm for antibiotic prophylaxis infective endocarditis in dental procedures.

IE or prosthetic heart valve, cardiac transplantation recipients with cardiac valvulopathy, and some patients with congenital heart disease can still benefit from antibiotic prophylaxis (Table I). ${ }^{(2)}$

Dental procedures that present the highest risk for IE are more clearly defined, as seen in Table II. The AHA guidelines classified all procedures that involve the direct manipulation of gingival tissue, manipulation of the periapical region of teeth, or procedures involving perforation and compromise of the oral mucosa as high-risk procedures. These procedures represent cases for which the abovementioned at-risk groups should receive antibiotic prophylaxis. In addition, specific procedures with a low risk of transient bacteraemia were identified as not requiring antibiotic prophylaxis.

\section{Choice of antibiotic prior to dental procedures}

For patients undergoing dental procedures in whom prophylaxis is appropriate, the preferred regimen is oral amoxicillin $2 \mathrm{~g}$, given 30-60 minutes before the procedure (Fig. 1). Patients who are allergic to penicillin or ampicillin can be treated with clindamycin (600 mg), azithromycin (500 mg) or clarithromycin (500 mg)
Table II. Dental procedures at high and low risks of transient bacteraemia.*

\begin{tabular}{|c|c|}
\hline High risk & $\begin{array}{l}\text { Lower risk (no need for } \\
\text { antibiotic prophylaxis) }\end{array}$ \\
\hline $\begin{array}{l}\text { Dental procedures that involve } \\
\text { manipulation of either gingival } \\
\text { tissue or periapical region of } \\
\text { teeth or perforation of teeth or } \\
\text { perforation of oral mucosa }\end{array}$ & $\begin{array}{l}\text { Routine anesthetic injections } \\
\text { through noninfected tissue }\end{array}$ \\
\hline Suture removal & Dental radiographs \\
\hline $\begin{array}{l}\text { Periodontal procedures (scaling, } \\
\text { root planning, probing, surgery, } \\
\text { recall maintenance) }\end{array}$ & $\begin{array}{l}\text { Placement or removal of } \\
\text { prosthodontics or orthodontic } \\
\text { appliances }\end{array}$ \\
\hline Extractions & $\begin{array}{l}\text { Adjustment of orthodontic } \\
\text { appliances }\end{array}$ \\
\hline $\begin{array}{l}\text { Implant placement and } \\
\text { reimplantation of avulsed teeth }\end{array}$ & $\begin{array}{l}\text { Placement of orthodontic } \\
\text { brackets }\end{array}$ \\
\hline $\begin{array}{l}\text { Endodontic instrumentation or } \\
\text { surgery beyond apex }\end{array}$ & Shedding of deciduous teeth \\
\hline $\begin{array}{l}\text { Subgingival placement of } \\
\text { antibiotic fibres or strips }\end{array}$ & $\begin{array}{l}\text { Bleeding from trauma to lips or } \\
\text { oral mucosa }\end{array}$ \\
\hline \multicolumn{2}{|l|}{$\begin{array}{l}\text { Intraligamentary local } \\
\text { anaesthetic injections }\end{array}$} \\
\hline \multicolumn{2}{|l|}{$\begin{array}{l}\text { Prophylactic cleaning of teeth or } \\
\text { implants }\end{array}$} \\
\hline \multicolumn{2}{|l|}{ Biopsies } \\
\hline Placement of orthodontic bands & \\
\hline
\end{tabular}

Table III. Regimens for a dental procedure.

\begin{tabular}{llll}
\hline Recommended & Agent & \multicolumn{2}{c}{ Regimen* } \\
\cline { 3 - 4 } regimen & & Adults & Children \\
\hline First-line (oral) & Amoxicillin & $2 \mathrm{~g}$ & $50 \mathrm{mg} / \mathrm{kg}$ \\
Allergic to penicillin or & Clindamycin, & $600 \mathrm{mg}$ & $20 \mathrm{mg} / \mathrm{kg}$ \\
ampicillin (oral) & $\begin{array}{l}\text { azithromycin or } \\
\text { clarithromycin }\end{array}$ & $500 \mathrm{mg}$ & $15 \mathrm{mg} / \mathrm{kg}$ \\
& Cla & $15 \mathrm{mg} / \mathrm{kg}$ \\
\hline
\end{tabular}

*Single dose 30-60 minutes before procedure.

(Table III). Patients who are unable to take oral medications can be treated with $2 \mathrm{~g}$ of intravenous or intramuscular ampicillin. Patients allergic to penicillin can be given intravenous or intramuscular clindamycin (600 mg).

\section{Special circumstances}

Special circumstances regarding antibiotic prophylaxis for IE include:

1) In patients receiving antibiotics for other indications at the time of the dental procedure, an alternate antibiotic of a different class should be chosen, e.g. in a patient receiving penicillin for rheumatic fever prophylaxis who undergoes invasive dental procedure, clindamycin, cephalexin or azithromycin may be used.

2) Intramuscular injections should be avoided in patients who are on anticoagulation. Intravenous antibiotics may be used if the patient is unable to take the medication orally.

3) In patients with a history of IE, involvement of previous organism should be checked and broader spectrum antibiotic coverage considered. 
Recent percutaneous intervention: gingival bleeding vs. stent thrombosis ${ }^{(6)}$

Dental surgery can generally be performed on patients taking a daily dose of aspirin, and if necessary, clopidogrel may be administered. Precautions can be adopted by the dental surgeons if they are aware of the use of antiplatelets before the procedure. These include utilising a local anaesthetic containing adrenaline, noradrenaline or both, performing such elective cases in the morning to minimise the likelihood of bleeding occurring after hours, and paying more attention to haemostasis using local measures. Therefore, the indication for antiplatelet therapy should be clearly stated on the memorandum to our dental colleagues. There may be additional caution that they need to anticipate if the procedure has a high risk of bleeding, especially in patients with prior coronary artery stenting.

Despite the observation that dual antiplatelet therapy increases the likelihood of bleeding in most surgical procedures, the consequences of bleeding are less significant than those of stent thrombosis. Although the risk of acute stent thrombosis after stopping antiplatelet therapy is low, it carries a mortality rate of about $50 \%$ when it does occur. If the dental procedure is an elective one, it is advisable to defer the surgery until the dual antiplatelet therapy is completed (6-12 weeks following bare metal stents and 12 months following drug-eluding stents). However, if the procedure is time-sensitive, these patients should be referred to their primary cardiologist for advice. The proposed procedures, their indications, urgency and alternatives should be clearly communicated so that the cardiologist can make the appropriate recommendations.

You write the following memorandum to Dr Tan, the patient's dentist:

Thank you for taking care of Mr Jack's dental health. Jack sees me for his hyperlipidaemia, and he is currently on oral simvastatin $20 \mathrm{mg}$ ON. Please avoid the use of macrolides in view of the possible drug interactions with statins. I also co-manage his mitral valve prolapse and chronic ischaemic heart disease with Dr Chan, his cardiologist. He had undergone an angioplasty without stents six years ago and has been on daily aspirin since then. Please pay more attention to haemostasis measures after his tooth extraction. Please feel free to contact me for any further information.

\section{TAKE HOME MESSAGES}

1. Antibiotic prophylaxis is only recommended when patients with cardiac conditions at high risk for IE are undergoing high-risk dental procedures.

2. IE is better prevented by good dental hygiene than prophylactic antibiotic therapy, as transient bacteraemia is more common in daily activities, such as the brushing and flossing of teeth.
3. The risk of adverse drug reactions outweighs the benefit of antibiotic prophylaxis in the prevention of IE in moderateto low-risk patients.

4. Dental and other noncardiac surgeries can generally be performed on patients taking a daily dose of aspirin.

5. Patients with prior coronary artery stenting on antiplatelet therapy should be referred to their primary cardiologist for further advice before any surgery.

ABSTRACT Dental surgery is very common, and it is important for our dental colleagues to understand the medical history and chronic medications of our co-managed patients. Antibiotic prophylaxis is currently recommended only for patients at high risk for infective endocarditis when undergoing high-risk dental procedures. Good dental hygiene can prevent more infective endocarditis than prophylactic antibiotic therapy, as transient bacteraemia is common in daily activities such as the brushing and flossing of teeth. Most dental surgeries can generally be performed on patients taking a daily dose of aspirin, but the dentist must be able to assess the risk-benefit ratio of employing local measures of haemostasis versus stopping the antiplatelet therapy. Patients on antiplatelet with recent coronary artery stenting should be referred to their primary cardiologist regarding the cessation of these agents before any surgery.

Keywords: antibiotic prophylaxis, antiplatelet therapy, dental surgery, infective endocarditis

Singapore Med J 2013; 54(1): 11-14

\section{REFERENCES}

1. Burnette-Curley D, Wells V, Viscount H, et al. FimA, a major virulence factor associated with Streptococcus parasanguis endocarditis. Infect Immun 1995; 63:4669-74.

2. Wilson W, Taubert KA, Gewitz M, et al. Prevention of infective endocarditis: guidelines from the American Heart Association: a guideline from the American Heart Association Rheumatic Fever, Endocarditis, and Kawasaki Disease Committee, Council on Cardiovascular Disease in the Young, and the Council on Clinical Cardiology, Council on Cardiovascular Surgery and Anesthesia, and the Quality of Care and Outcomes Research Interdisciplinary Working Group. Circulation 2007; 116:1736-54.

3. Pallasch TJ. Antibiotic prophylaxis: problems in paradise. Dent Clin North Am 2003; 47:665-79.

4. Durack DT. Prevention of infective endocarditis. N Engl J Med 1995; 332:38-44.

5. Nishimura RA, Carabello BA, Faxon DP, et al. ACC/AHA 2008 guideline update on valvular heart disease: focused update on infective endocarditis: a report of the American College of Cardiology/American Heart Association Task Force on Practice Guidelines: endorsed by the Society of Cardiovascular Anesthesiologists, Society for Cardiovascular Angiography and Interventions, and Society of Thoracic Surgeons. Circulation 2008; 118:887-96.

6. The Cardiac Society of Australia and New Zealand. Guidelines for the use of antiplatelet therapy in patients with coronary stents undergoing non-cardiac surgery [online]. Available at: www.csanz.edu.au/Portals/0/ Guidelines/Practice/Use\%20of\%20antiplatelet $\% 20$ therapy $\% 20 \mathrm{in} \% 20$ patients $\% 20$ with $\% 20$ coronary $\% 20$ stents $\% 20$ undergoing $\% 20$ noncardiac\%20surgery.pdf. Accessed December 20, 2012. 


\section{SINGAPORE MEDICAL COUNCIL CATEGORY 3B CME PROGRAMME}

\section{(Code SMJ 201301B)}

1. Staphylococcus aureus is the most common organism for native valve infective endocarditis (IE).

2. Streptococcus viridans is the most common organism for native valve IE.

3. Daily activities, such as the brushing of teeth, are more common causes of transient bacteraemia than dental procedures.

4. There is no randomised control trial showing that prophylactic antibiotics reduce the incidence of IE post dental procedures.

5. Amoxicillin is the first drug of choice for antibiotic prophylaxis for IE prior to dental procedures.

6. Patients at high risk of IE who are already receiving antibiotics at the time of the dental procedure do not require additional antibiotics during the dental procedure.

7. Intramuscular injections of antibiotics should be avoided in patients on anticoagulation who cannot take oral medication.

8. Intravenous injections of antibiotics should be avoided in patients on anticoagulation who cannot take oral medication.

9. The risk of developing IE post dental procedure is 1:100,000 in the general population.

10. Dental procedures cannot be performed on patients taking a daily dose of aspirin.

11. It is the standard advice given by any competent Family Physician to patients with prior coronary artery stenting on aspirin to stop their intake of aspirin one week before the dental procedure and to resume it more than 24 hours after the procedure if they do not experience any bleeding from the site.

According to the current clinical guidelines, the following patients will require antibiotics prophylaxis:

12. Mr Lee, a 60-year-old man with bioprosthetic aortic valve replacement (AVR) undergoing dental cleaning.

13. Mrs Chen, a 40-year-old woman with moderate mitral valve regurgitation secondary to mitral valve prolapse undergoing dental extraction. (refer to 3.5.3 - AHA IE update)

14. Mr Tan, a 60-year-old man with bioprosthetic AVR undergoing dental fluoride treatment.

15. Ms Mary, a 60-year old woman with isolated secundum atrial septal defect two months post-patch repair undergoing dental extraction.

16. Mr Roberts, a 40-year-old man with a history of Staphylococcus aureus IE five years ago undergoing scaling.

17. Mr Sivanaesan, a 50-year-old man with ventricular septal defect that was surgically repaired one year ago, without pulmonary hypertension, undergoing dental extraction.

18. Mr Rajendran, a 50-year-old man with ventricular septal defect that was surgically repaired two months ago undergoing gingival biopsy.

19. Mrs Au Yong, a 60-year old woman with severe mitral stenosis undergoing dental extraction.

20. Mrs Chee, a 60-year-old woman with severe mitral stenosis undergoing dental X-ray.

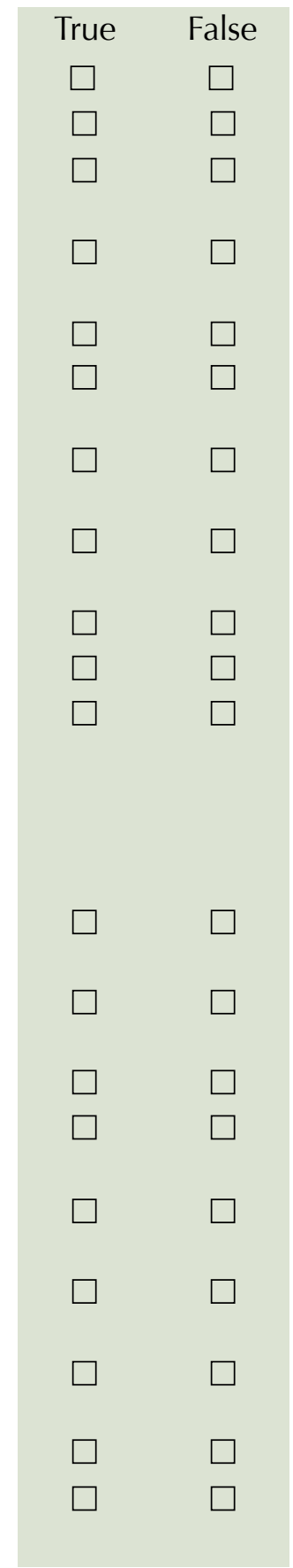

\section{Doctor's particulars:}

Name in full

MCR number

Specialty:

Email address

SUBMISSION INSTRUCTIONS:

(1) Log on at the SMJ website: http://www.sma.org.sg/cme/smj and select the appropriate set of questions. (2) Select your answers and provide your name, email address and MCR number. Click on "Submit answers" to submit.

\section{RESULTS:}

(1) Answers will be published in the SMJ March 2013 issue. (2) The MCR numbers of successful candidates will be posted online at www.sma.org.sg/cme/smj by 22 February 2013. (3) All online submissions will receive an automatic email acknowledgement. (4) Passing mark is $60 \%$. No mark will be deducted for incorrect answers. (5) The SMJ editorial office will submit the list of successful candidates to the Singapore Medical Council. (6) One CME point is awarded for successful candidates. 